\title{
Serological Rapid Test for Diagnosis of SARS-COVv- 2 Works Also on Gastro-intestinal Tissue Samples of COVID-19 Patients: Practical Aspects of Single Center Observational Study.
}

\section{Lorenzo Dioscoridi ( $\nabla$ dioscoridi.lorenzo@virgilio.it)}

ASST Grande Ospedale Metropolitano Niguarda: Azienda Socio Sanitaria Territoriale Grande Ospedale Metropolitano Niguarda https://orcid.org/0000-0003-4975-018X

\section{Mutaz Massad}

ASST Grande Ospedale Metropolitano Niguarda: Azienda Socio Sanitaria Territoriale Grande Ospedale Metropolitano Niguarda

\section{Edoardo Forti}

Niguarda Ca Granda Hospital: Azienda Socio Sanitaria Territoriale Grande Ospedale Metropolitano Niguarda

\section{Francesco Pugliese}

Niguarda Hospital: Azienda Socio Sanitaria Territoriale Grande Ospedale Metropolitano Niguarda

\section{Marcello Cintolo}

Niguarda Hospital: Azienda Socio Sanitaria Territoriale Grande Ospedale Metropolitano Niguarda

\section{Giulia Bonato}

Niguarda Hospital: Azienda Socio Sanitaria Territoriale Grande Ospedale Metropolitano Niguarda

\section{Roberto Rosa}

Niguarda Hospital: Azienda Socio Sanitaria Territoriale Grande Ospedale Metropolitano Niguarda

\section{Massimiliano Mutignani}

Niguarda Hospital: Azienda Socio Sanitaria Territoriale Grande Ospedale Metropolitano Niguarda

\section{Research Article}

Keywords: COVID-19, SARS-COV-2, serological rapid test, gastrointestinal COVID-19.

Posted Date: May 19th, 2021

DOI: https://doi.org/10.21203/rs.3.rs-451259/v1

License: (c) (1) This work is licensed under a Creative Commons Attribution 4.0 International License. Read Full License 


\section{Abstract}

SARS-COV-2 infection spreading becomes a long and challenging medical question. The possibility to improve the diagnosis of SARS-COV-2 infection in digestive endoscopy is important because gastrointestinal symptoms can be the presenting symptoms of COVID-19.

We tried to obtain a fast and "bedside" diagnosis of gastrointestinal COVID-19 by performing serological rapid test to verify the presence of SARS-COV-2 in gastrointestinal mucosal specimens.

From the $4^{\text {th }}$ to the $30^{\text {th }}$ January 2021, regular mucosal biopsies were taken from stomach, ileum or colon of 10 COVID-19 patients (7M, 3F, mean age: 49.7 y.o.) and from 10 negative patients ( $6 \mathrm{M}, 4 \mathrm{~F}$, mean age: 50 y.o.) according to standard clinical indications. One specimen for each patient was placed in a sterile test-tube with 5 drops of standard reagent for rapid serological test for 10 minutes.

After that period, both the specimen and the drops were put on the platform for serological rapid tests. In all COVID-19 patients, tests were positive for both IgG and IgM bands (and control bands, confirming that the test worked properly). Otherwise, the analysis of gastrointestinal specimen of negative patients showed only the control band.

No differences were found for different specimens (stomach, colon or ileum).

Statistical analysis conducted to compare the results of the two groups confirmed the difference between COVID-19 positive and negative groups.

Applying this kind of analysis, we can immediately verify if gastrointestinal symptoms (especially diarrhea) of a non-tested patient are related to SARS-COV-2 infection and we can use this test as a rapid test in case of suspected endoscopic findings to confirm the association with SARS-COV-2 infection.

In the end, the test can contribute to help in the differential diagnosis of gastrointestinal manifestations considering the long-term management of SARS-COV-2 infections.

\section{Introduction}

SARS-COV-2 infection spreading becomes a long and challenging medical question. Serological rapid tests are now increasingly used worldwide to detect previously or actively infected patients or health care providers from COVID-19, especially in ambulatory settings [1-2].

Considering that gastrointestinal involvement is not uncommon and can represents the only manifestation of COVID-19 [3], the possibility to improve the diagnosis in digestive endoscopy is important.

We tried to obtain a fast and "bedside" diagnosis of gastrointestinal COVID-19 by using serological rapid test to verify the presence of SARS-COV-2 in mucosal specimens of gastrointestinal system. 
No previously available literature analyzed this potential application. The hypothesis is that if serological rapid tests detect the antibodies anti-SARS-COV-2 present in blood, the same test can be able to detect the same antibodies on other tissues.

\section{Methods}

From the 4th to the 30th January 2021, regular mucosal biopsies were taken from stomach, ileum or colon of 10 COVID-19 patients (7M, 3F, mean age: 49.7 y.o.) according to standard clinical indications. One specimen for each patient was placed in a sterile test-tube with 5 drops of standard reagent for rapid serological test for 10 minutes.

After that period, both the specimen and the drops were put on the platform for serological rapid tests. The serological rapid tests studied both IgG and IgM with a declared sensitivity of $100 \%$ for IgG and $85 \%$ for lgM.

To confirm the results, 10 negative patients (6M, 4F, mean age: 50 y.o.) undergoing biopsies for standard indications were also included in the study using the same process.

Eligibility criteria were the standard indication for digestive endoscopy, standard indication to take biopsies and signature of informed consent for the present study.

The main outcome was the verify the application of serological rapid tests on tissue samples in terms of positive or negative results. The assessment method for the same for the two groups.

Uncertain diagnosis of positive or negative cases was considered a potential confounder and recent contact with patients positive to SARS-COV- 2 infection was considered a potential bias. Thus, both conditions were exclusion criteria for the study.

The study size was arrived at the described number on the base of the patient total number during the study period and to reach statistically significance.

Statistical analysis was conducted to compare the results of the two groups of patients using Chisquared test.

\section{Discussion}

In all 10 positive cases, serological tests on tissue specimen were positive for both IgG and IgM bands (and control bands, confirming that the test worked properly) (Fig. 1). No differences were found for different specimens (stomach, colon or ileum).

The analysis of the specimen of negative group by serological rapid tests showed only the control band in all the cases. 
Statistical analysis conducted to compare the results of the two groups of patients using Chi-squared test confirmed the difference between COVID-19 positive and negative groups $(p<0.05)$.

Few interesting practical implications may come into view from this finding.

Firstly, we can immediately verify if gastrointestinal symptoms (especially diarrhea) of a non-tested patient are related to SARS-COV-2 infection just taking few biopsies.

Secondly, we can use this test as a rapid test (i.e. for $\mathrm{H}$. pylori) in case of suspected endoscopic findings (i.e. peptic ulcers, gastric erosions [4]) to confirm the association with SARS-COV-2 infection.

Limitations of our study are the variability of the tissue specimen and the single center experience. For these reasons, further studies would be able to confirm the external validity of our results.

In the end, the test can contribute to help in the differential diagnosis of gastrointestinal manifestations considering the long-term management of SARS-COV-2 infections [5].

\section{Declarations}

Funding: No funding sources were available for the present study.

Conflict of interest statement: The authors declare no conflict of interest related to the present paper.

Ethics approval: The study was approved by our internal Ethical Committee (n.008/2021).

Consent to participate: The patients signed informed consent to participate to the study.

Consent for publication: The patients approved the publication of the sensible and personal data included in the paper.

Availability of data and material: Database and statistical analysis process are available.

Code availability: $n / a$

Authors' contributions: LD and MM wrote the paper; EF and FP collected the data; GB and RR analyze the data; MM revised the manuscript. All the authors approved the final version.

\section{References}

1. Pallett SJC, Rayment M, Patel A, Fitzgerald-Smith SAM, Denny SJ, Charani E, Mai AL, Gilmour KC, Hatcher J, Scott C, Randell P, Mughal N, Jones R, Moore LSP, Davies GW. Point-of-care serological assays for delayed SARS-CoV-2 case identification among health-care workers in the UK: a prospective multicentre cohort study. Lancet Respir Med. 2020 Sep;8(9):885-894. doi: 
10.1016/S2213-2600(20)30315-5. Epub 2020 Jul 24. Erratum in: Lancet Respir Med. 2020 Jul 30;: PMID: 32717210; PMCID: PMC7380925.

2. Deeks JJ, Dinnes J, Takwoingi Y, Davenport C, Spijker R, Taylor-Phillips S, Adriano A, Beese S, Dretzke J, Ferrante di Ruffano L, Harris IM, Price MJ, Dittrich S, Emperador D, Hooft L, Leeflang MM, Van den Bruel A; Cochrane COVID-19 Diagnostic Test Accuracy Group. Antibody tests for identification of current and past infection with SARS-CoV-2. Cochrane Database Syst Rev. 2020 Jun 25;6(6):CD013652. doi: 10.1002/14651858.CD013652. PMID: 32584464; PMCID: PMC7387103.

3. Elshazli RM, Kline A, Elgaml A, Aboutaleb MH, Salim MM, Omar M, Munshi R, Mankowski N, Hussein $\mathrm{MH}$, Attia AS, Toraih EA, Settin A, Killackey M, Fawzy MS, Kandil E. Gastroenterology manifestations and COVID-19 outcomes: A meta-analysis of 25,252 cohorts among the first and second waves. J Med Virol. 2021 Feb 2. doi: 10.1002/jmv.26836. Epub ahead of print. PMID: 33527440.

4. Massironi S, Viganò C, Dioscoridi L, Filippi E, Pagliarulo M, Manfredi G, Conti CB, Signorelli C, Redaelli $A E$, Bonato G, liritano E, Frego R, Zucchini N, Ungari M, Pedaci M, Bono F, Di Bella C, Buscarini E, Mutignani M, Penagini R, Dinelli ME, Invernizzi P. Endoscopic Findings in Patients Infected With 2019 Novel Coronavirus in Lombardy, Italy. Clin Gastroenterol Hepatol. 2020 Sep;18(10):2375-2377. doi: 10.1016/j.cgh.2020.05.045. Epub 2020 May 30. PMID: 32480008; PMCID: PMC7260560.

5. Stollman N, Kefalas CH. Today's Challenges and Tomorrow's Practice: Impact of COVID-19 on the Future of GI Practices. Am J Gastroenterol. 2021 Feb 1;116(2):227-228. doi:

10.14309/ajg.0000000000001066. PMID: 33566557.

\section{Figures}


A

COVID-19

$C$
$\lg G$
$\lg M$

$C$
$\lg G$
$\lg M$

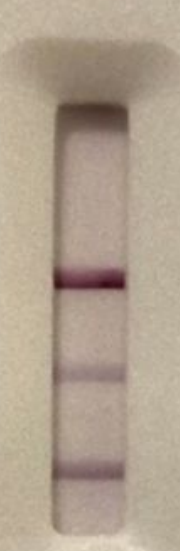

B

COVID-19

C IgG IgM
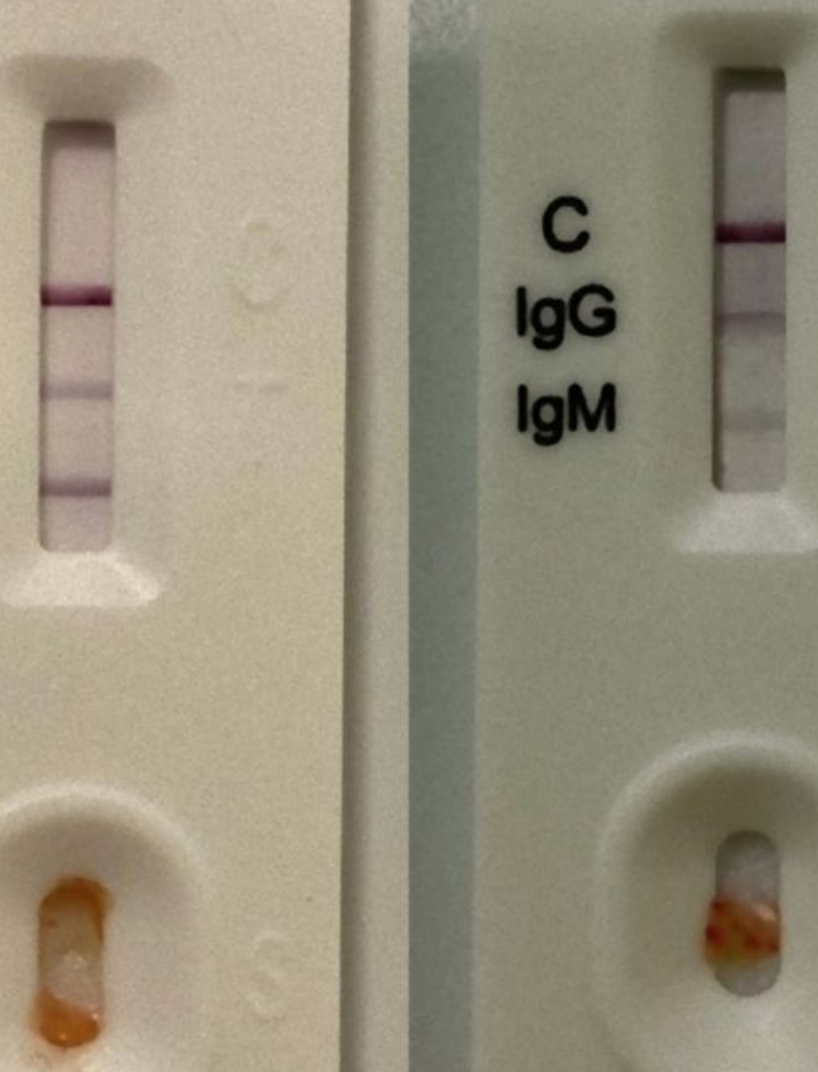